\title{
KNOWLEDGE OF WOMEN; SUPPLEMENTATION OF FOLIC ACID IN PERICONCEPTIONAL PERIOD
}

1. University of Health Sciences Lahore

2. Akhtar Saeed Medical \& Dental College Lahore

3. University of Health Sciences Lahore

4. KMU, Institute of Nursing Sciences, Khyber Medical University Peshawar

Corresponding Address:

Ms. Anum Fatima,

Nursing instructor

University of Health

Sciences Lahore

anumfatima882@yahoo.com

Article received on: 05/05/2016

Accepted for publication: 20/06/2016

Received after proof reading: $04 / 07 / 2016$

\begin{abstract}
Anum Fatima ${ }^{1}$, Nadia Saif ${ }^{2}$, Mansoor Ghani ${ }^{3}$, Sardar $\mathrm{Ali}^{4}$
ABSTRACT... Objectives: Around 50 to $70 \%$ of the neural tube defects can be prevented if a woman consumes sufficient folic acid daily before conception and throughout first trimester of her pregnancy. Therefore, the women should be well aware about the apt supplementation of folic acid to mitigate those miseries that can be resulted from its deficiency. Study Design: A descriptive survey design. Setting: Obstetrical OPDs of Lahore General Hospital, Lady Aitchison Hospital, Jinnah Hospital Lahore, DHQ Hospital Multan, DHQ Hospital Faisalabad, and DHQ Hospital Rawalpindi. Methodology: A total of 300 pregnant women were studied to assess the level of knowledge and practices among women regarding use of folic acid before and during pregnancy. Non probability convenient sampling technique was used for the purpose. Data was collected by a self administered questionnaire and was analysed by SPSS version 20 . A p-value of $\leq 0.05$ was considered statistically significant. Results: The results signified that a major fraction of pregnant women $227(76 \%)$ were having poor level of knowledge as they scored less than $50 \%$ on knowledge based questions in the questionnaire. Only $4 \%$ were distinguished with excellent knowledge according to arbitrary scale, which were made-up to be a very low percentage. Conclusion: Findings of the study suggested that the knowledge of the women regarding folic acid supplementation is insufficient that may in response lead to increase risk for the incidences of neural tube defect.
\end{abstract}

Key words: $\quad$ Knowledge, folic Acid, Neural Tube Defects, Periconceptional Period

Article Citation: Fatima A, Saif N, Ghani M, Ali S. Knowledge of women; supplementation of folic acid in periconceptional period. Professional Med J 2016;23(7):828-834. DOI: $10.17957 / T P M J / 16.3439$

\section{INTRODUCTION}

Folic acid is one of the most crucial naturally occurring vitamins which play an important role to overcome the growth retardation tribulations in fetus and to prevent a range of nutritional disorders at various junctures of reproductive and human life cycles. The pertinent supplementation of folic acid among women throughout the first trimester in pregnancy can prevent neural tube defects by around 50 to $70 \% .^{1,2}$ Neural tube defects are the most pervasive birth defects, contributing not only to infant mortality but also lead to some serious consequences that affect the children in almost all the spheres of life. There has been an experimental and epidemiological confirmation that an increased periconceptional (before \& during pregnancy) supplementation of folic acid decreases the risk of these birth defects by manifold. $3,4,5$
Folic acid, a micronutrient, is an important constituent of the prophylactic interventions that is crucial for the customary development of the spinal column, brain and skull of the fetus. Even though exact mechanism is not clear, a genetic or nutritional defect in homocysteine metabolism most likely implicates in the pathogenesis of neural tube and related congenital defects. Eggs, leafy vegetables, meat, liver, diary product etc are the major sources of folic acid that need to be encouraged during pregnancy to overcome the calamities of congenital defects and keep the fetus as well as the mothers' healthy in all respects. ${ }^{6,7,8}$

Women who intend to be pregnant should have a plasma folate concentration of $900 \mathrm{nmol} / \mathrm{L}$. Folic acid is a water soluble vitamin, and its excretion via urine increases in pregnancy which leads to a decrease in plasma folic acid levels. Furthermore, 
imbalanced diet and absence of folic acid supplementation lead to more reduced levels. ${ }^{9}$ As the human body is unable to synthesize this vitamin so it should be taken in the form of diet or supplements in order to surmount the genetic and nutritional influences that lead to birth defects. ${ }^{10}$ The incidence of neural tube defects in Pakistan is relatively high ${ }^{11}$ and it is estimated as 13.90 per 1000 live births ${ }^{12}$ whereas in United Kingdom (UK), United states of America (USA), Denmark and Oman it is around 1-5 per 1000 live births. ${ }^{13,14,15}$ This low prevalence rate is due to increased knowledge of folic acid consumption in periconceptional period. Irrespective of food fortification planning, folic acid publicity as a significant supplement will probably be required in most of the countries to increase level of knowledge regarding folic acid among women of child bearing age. ${ }^{16,17,18}$ Most of the women are aware of effectiveness of this supplement but still they don't take it periconceptionally. Women of child bearing age may correlate folic acid more with pregnancy and less with pre-pregnancy. The most important group to be focused in this regard should be the women belong to low socioeconomic strata, young age, low parity and decreased educational status. ${ }^{18,19}$

In addition, poor practices, inadequate knowledge and absence of screening program for antenatal recognition of Neural Tube Defects further worsen the situation. Therefore, there was a dire need to assess the level of knowledge about folic acid supplementation among women before and during pregnancy in the current study to ensure the use of folic acid in periconceptional period, which is considered to be the critical for prevention of these devastating defects in the baby.

\section{METHODOLOGY}

A simple descriptive survey design was carried out to conduct this study in the Obstetrical OPDs of local teaching hospitals in Lahore. A total of 300 pregnant women were studied for the purpose to assess the level of knowledge and practices among women regarding use of folic acid before and during pregnancy. The sample was taken from Lahore General Hospital, Lady Aitchison Hospital, Jinnah Hospital Lahore, DHQ Hospital Multan, DHQ Hospital Faisalabad, and DHQ Hospital Rawalpindi by using convenient sampling technique. The data was collected by selfadministered questionnaire. The questionnaire was developed precisely in English and then was translated into Urdu language to assess the knowledge of pregnant women regarding folic acid supplementation. All the ethical aspects of study were taken care of. Informed consent was taken for voluntary participation.

A pilot study was also carried out on 30 participants of all relevant teaching Hospitals that were $10 \%$ of actual sample size. The internal consistency of 0.684 was calculated by applying Cronbach's a which depicted that instrument was reliable and consistent for data compilation of the current study survey design. The Cronbach's a value of 0.60 is acceptable for reliability of a scale..$^{20,21,22,23}$

\section{STATISTICAL ANALYSIS}

The data was analysed by SPSS version 20 and was represented in the form of figures, tables and percentages. Frequencies and percentages were calculated for categorical variables. Association of demographic variables with level of knowledge and practices of folic acid supplementation was also identified by applying Chi-square test. A $p$-value of $\leq 0.05$ was considered statistically significant.

\section{RESULTS}

To analyze the number of participants according to their age, it was noted that $137(45.67 \%)$ out of 300 pregnant women were in age 18-24 years, $126(42 \%)$ were in $25-30$ years category, $33(11 \%)$ were in $31-36$ years category and very few (1.33\%) were in $37-42$ years category.

For the educational status it was noted that 141 (47\%) out of 300 pregnant women were either illiterate or with primary education only. A considerable number of $108(36 \%)$ were having Matric or F.A/FSc qualification, whereas, 44 (14.6\%) were having B.A/ B.ED, M.A/MSc. The pregnant women having medical education and 
knowledge about folic acid supplementation were only $7(2.3 \%)$.

Occupational status seen in this study showed that out of 300 pregnant women $89 \%$ (268) were housewives, whereas $13(4.3 \%)$ were selfemployed, and 18 (6\%) were employed in institutions.

Analysis of parity (number of children) showed that majority of women; $91(30.33 \%)$ out of 300 pregnant were primigravida, women having one child were 77 (26\%), women having two were $68(23 \%)$, women having three were $35(12 \%)$; However, women having four and five children were very few i.e., $25(8.3 \%)$ and $4(1.33 \%)$ respectively.

The study showed that out of 300 pregnancies, only $20(6.6 \%)$ were planned whereas; 280 (93.3\%) were unplanned.

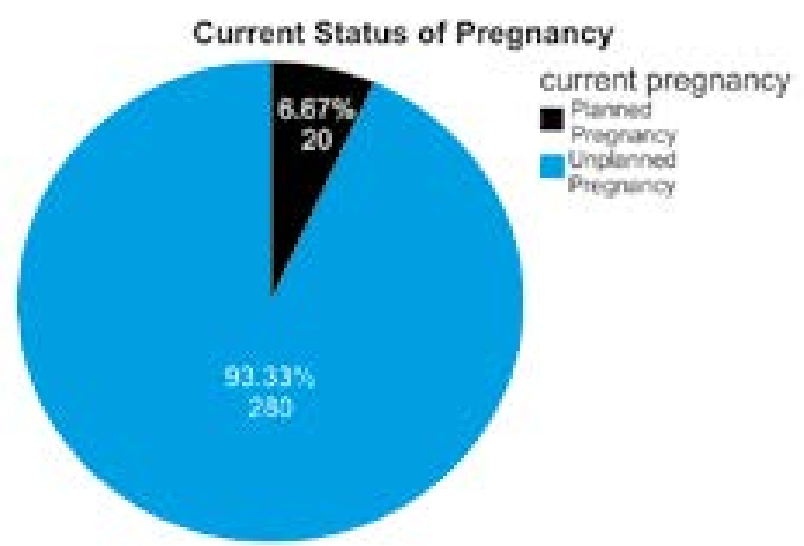

Figure-1. Current status of pregnancy

The primary objective was to assess the knowledge of pregnant women about folic acid use before and during pregnancy according to preselected criteria of knowledge level indicators ${ }^{24}$

Which are as follows:

Excellent Knowledge:

Good Knowledge:

Average Knowledge:

Poor Knowledge:

More than $80 \%$

$65-80 \%$

$50-64 \%$

Less than $50 \%$

It was identified that $14(4 \%)$ out of 300 pregnant women had excellent knowledge due to higher educational level and good occupational status. 15 (5\%) had good knowledge, 44 (14\%) had average knowledge and a large number of participants 227 (75\%) had poor knowledge. The knowledge level was computed by the following knowledge related questions of the study tool, 1 (what is your knowledge about folic acid), 2(what is primary benefit of taking folic acid on outcome of your pregnancy?), 3 (what is the best time to start taking folic acid?) 4 (what are the good sources of folic acid), 5 (Do you think that folic acid use may help to prevent certain birth defects?) \& 14 (have you ever taken Folic Acid pills, If yes then how many?). It is worth mentioning that $65 \%$ women gave wrong answer to question $1,93 \%$ to 2 and 3 , $74 \%$ to 4 , and surprisingly in response to question 14 majority of respondents gave right answer and only $33 \%$ provided wrong information.

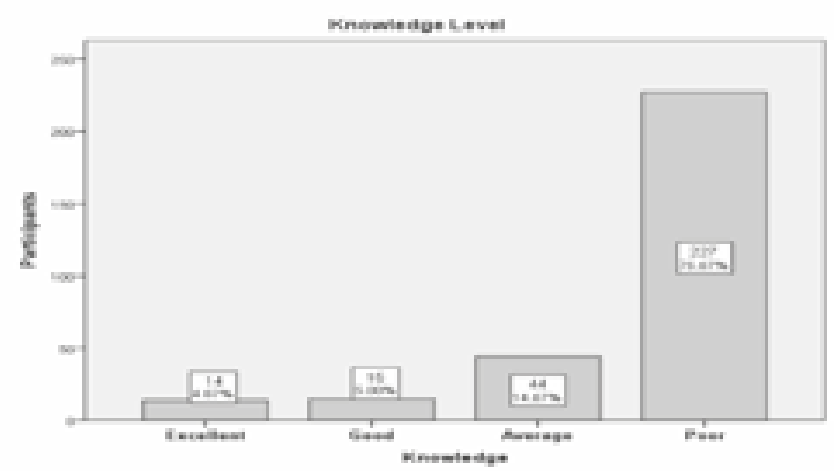

Figure-2. Knowledge level

Cross tabulation of knowledge level and use of folic acid before pregnancy was performed by using Chi square test at $P$-value $\leq 0.05$. It was found that 265 out of 300 were not using folic acid before pregnancy at any time and had poor level of knowledge regarding periconceptional folic acid supplementation. The computed P-Value was 0.001 that shows a statistically significant association between level of knowledge and use of folic acid before pregnancy.

Chi square test was used in order to check the association between level of knowledge and time period of using folic acid in current pregnancy. A P-value $\leq 0.05$ was considered statistically significant. It was identified that majority of 


\begin{tabular}{|c|c|c|c|c|c|c|}
\hline \multirow{2}{*}{$\begin{array}{l}\text { When start using folic acid before } \\
\text { pregnancy }\end{array}$} & \multicolumn{4}{|c|}{ Level of Knowledge } & \multirow[b]{2}{*}{ Total } & \multirow{2}{*}{ P-Value } \\
\hline & Excellent & Good & Average & Poor & & \\
\hline One month before pregnancy & $3(42 \%)$ & $2(29 \%)$ & $2(9 \%)$ & $0(0.0 \%)$ & $7(100 \%)$ & \\
\hline Two months before pregnancy & $4(17.4 \%)$ & $2(8.7 \%)$ & $1(4.3 \%)$ & $16(70 \%)$ & $23(100 \%)$ & 0.001 \\
\hline Three months before pregnancy & $2(40 \%)$ & $2(40 \%)$ & $1(20 \%)$ & $0(0.0 \%)$ & $5(100 \%)$ & \\
\hline No use at all & $5(1.9 \%)$ & $9(3.4 \%)$ & $40(15 \%)$ & $211(79.6 \%)$ & $265(100 \%)$ & \\
\hline Total & $14(4.7 \%)$ & $15(5 \%)$ & $44(14.7 \%)$ & $227(75.7 \%)$ & $300(100 \%)$ & \\
\hline
\end{tabular}

\begin{tabular}{|c|c|c|c|c|c|c|}
\hline \multirow{2}{*}{$\begin{array}{c}\text { When Start using Folic Acid } \\
\text { during Pregnancy }\end{array}$} & $\begin{array}{c}\text { Excellent } \\
\mathbf{n}(\%)\end{array}$ & $\begin{array}{c}\text { Good } \\
\text { n (\%) }\end{array}$ & $\begin{array}{c}\text { Average } \\
\text { n (\%) }\end{array}$ & $\begin{array}{c}\text { Poor } \\
\text { n (\%) }\end{array}$ & Total & P-Value \\
\hline After Pregnancy Test & $3(13.6 \%)$ & $1(4.5 \%)$ & $3(14 \%)$ & $15(68 \%)$ & $22(100 \%)$ & \\
\hline During Pregnancy after any visit & $4(2.3 \%)$ & $9(5.2 \%)$ & $35(20 \%)$ & $125(72 \%)$ & $173(100) \%$ & 0.001 \\
\hline During Pregnancy before visit & $6(35 \%)$ & $4(23 \%)$ & $4(23 \%)$ & $3(17 \%)$ & $17(100) \%$ & \\
\hline No use at all & $1(1.1 \%)$ & $1(1.1 \%)$ & $2(2.3 \%)$ & $84(95.5 \%)$ & $88(100 \%)$ & \\
\hline
\end{tabular}

Table-II. Association of level of knowledge with folic acid supplementation during pregnancy

pregnant women, 125 (72\%) were not using folic acid during pregnancy after any visit and had poor knowledge as well. Only six women were found using folic acid during pregnancy before antenatal visit and had excellent knowledge. A strong statistical association at $p$-value of 0.001 was found between the use of folic acid during pregnancy and level of knowledge

\section{DISCUSSION}

The present study showed unfavorable results with regard to the importance of folic acid supplementation before and during pregnancy in Pakistani women of reproductive age. A great number of pregnant women attained poor score on folic acid supplementation knowledge based questions.

Consumption of $400 \mu \mathrm{g}$ of folic acid daily at least 1 month before conception and in the early days of pregnancy could prevent $50-70 \%$ of neural tube defects, ${ }^{25,26,27,28}$ and the intake of nutrients must be increased during pregnancy to cope with the demands of both the growing fetus and the mother. ${ }^{7}$ Eating healthy food supplies the daily vitamin requirements, but most diets require supplementation. ${ }^{28}$ Worldwide, more than 20 million infants are born with a low birth weight annually, and, of these, 3.6 million die during the neonatal period, mainly due to malnutrition ${ }^{4,29,30}$ Antenatal nutritional advices in the general obstetric population appears to be effective in reducing the risk for preterm birth and increases the head circumference at birth. Balanced supplementation appears to improve fetal growth and may diminish the risks for stillbirth and infants born small-for-gestational age. ${ }^{31}$ Women therefore need to plan health education program to improve their attitudes, with special consideration during antenatal care.

In this study majority of women were having poor knowledge. The rationale behind this poor knowledge among pregnant women possibly was due to the lack of awareness, infrequent and fewer antenatal visits and visit at term pregnancy. Educational status was also seen influencing the use of folic acid and a study conducted among Saudi females on maternal knowledge and use of folic acid showed that the level of education was directly proportional to use of folic acid. ${ }^{32}$ Furthermore, unplanned pregnancies were found attributing to the level of knowledge.

In response to a question regarding knowledge about folic acid, 104 women (34.67\%) gave the correct answer that it is type of vitamin B. A similar study was conducted by Murad-Al- Holy in Saudi 
Arabia ${ }^{19}$, where $91 \%$ pregnant women knew about folic acid. According to March of Dimes Survey ${ }^{33}$ Report on Folic acid in 2008, it was found that $84 \%$ women were aware about folic acid. So, results of this study strongly recommend that knowledge about folic acid should be e provided through awareness campaigns and telecommunication media. Nursing staff and midwives should contribute to motivate and educate the women, as it is their professional and ethical obligation.

Parity also contributes to the level of knowledge and practices of folic acid use periconceptionally. A study was conducted in Abu Dhabi to assess the knowledge and check the practices of pregnant women regarding folic acid supplementation, it showed that only $32 \%$ women had a good knowledge and they were primigravida. ${ }^{2}$ On the contrary, the results of current study showed that multigravida women have better knowledge than primigravida women. The reason for such better knowledge of multigravida pregnant women was regular antenatal visits and follow-ups in their first pregnancy only due to the family consciousness. However, as the parity increased despite having adequate knowledge poor practices were found among these multigravida women because of their social attitudes and little awareness regarding the benefits of folic acid use in each pregnancy.

The employment/ occupational status was also found to impact the level of knowledge. It was explored among pregnant women of Iran that none of the employed women was in the lack of knowledge group. Most of individuals in low level knowledge group were housewives ${ }^{34}$. Although, Carmichael et al. was in disagreement of this notion showing that employed women do not have enough knowledge about folic acid intake.

The current status of pregnancy has a very strong influence on proper usage of folic acid. The unplanned pregnancies make the women least sensitive about the correct timing of folic acid usage. The rate of planned pregnancy seen in Saudi Arabia was $54 \%$ while unplanned was $46 \%$, and the results revealed increased awareness of folic acid usage among planned pregnant women. Similarly, in Croatia, $72 \%$ pregnancies were planned, among whom a significant association between planned pregnancies and folic acid usage was highlighted. These studies support the findings of the current study in which it was found that those who had excellent knowledge regarding supplementation of folic acid in periconceptional period were all having planned pregnancy.

Another discouraging area demonstrated by the results of this study was that majority of Pakistani pregnant women were having no information about the right time to start folic acid use and most of the information regarding this is provided by the healthcare provider when they already have conceived.

It was suggested from computed p-value $(0.001)$ that there was statistically significant association between knowledge level and use of folic acid in current pregnancy. Similarly, education, occupation, parity, income status, practice of using folic acid before pregnancy, practice of using folic acid after pregnancy, and level of knowledge, were found statistically significant.

\section{CONCLUSION}

On the basis of results obtained, it is concluded that in Pakistan, the pregnant women do not have adequate knowledge regarding folic acid supplementation that what is the most appropriate time to start folic acid.

Copyright@ 20 June, 2016.

\section{REFERENCES}

1. Ahmad B, Anam N, Khalid N, Mohsen R, Zaal L, Jadidy E, Alalati S. Perceptions of women of reproductive age about vitamin and folic acid supplements during pregnancy, Taibah University, Almadinah Almunawwarah, Kingdom of Saudi Arabia. Journal of Taibah University Medical Sciences. 2013 Dec 31; 8(3):199-204.

2. Al Hossani H, Abouzeid H, Salah MM, Farag HM, Fawzy E. Knowledge and practices of pregnant women about folic acid in pregnancy in Abu Dhabi, United Arab Emirates. East Mediterr Health J. 2010; 16(4):4027. 
3. Wilson RD, Johnson JA, Wyatt P, Allen V, Gagnon A, Langlois S, Blight C, Audibert F, Desilets V, Brock JA, Koren G. Pre-conceptional vitamin/folic acid supplementation 2007: the use of folic acid in combination with a multivitamin supplement for the prevention of neural tube defects and other congenital anomalies. Journal of obstetrics and gynaecology Canada: JOGC = Journal d'obstetrique et gynecologie du Canada: JOGC. 2007; 29(12):1003-26.

4. Wardlaw TM, editor. Low birthweight: country, regional and global estimates. UNICEF; 2004.

5. Antony AC. In utero physiology: role of folic acid in nutrient delivery and fetal development. AJCN. 2007 $1 ; 85(2): 598 S-603 S$.

6. Daly S, Cotter A, Molloy AE, Scott J. Homocysteine and folic acid: implications for pregnancy. In Seminars in vascular medicine 2005; 5(2):190-200.

7. Botto LD, Moore CA, Khoury MJ, Erickson JD. Neuraltube defects. NEJM. 1999; 341(20):1509-19.

8. Arias E, MacDorman MF, Strobino DM, Guyer B. Annual summary of vital statistics-2002. Pediatrics. 2003 1; 112(6):1215-30.

9. Oakley GP, Erickson JD, Adams MJ. Urgent need to increase folic acid consumption. JAMA. 1995; 274(21):1717-8.

10. Canfield MA, Przybyla SM, Case AP, Ramadhani T, Suarez $L$, Dyer J. Folic acid awareness and supplementation among Texas women of childbearing age. Preventive Medicine. 2006; 43(1):27-30.

11. Khattak ST, Naheed T, Akhtar S, Jamal T. Incidence and risk factors for Neural tube defects in Peshawar. Gomal Journal of Medical Sciences. 2004; 6(1).

12. Bener A, Al Maadid MG, Al-Bast DA, Al-Marri S. Maternal knowledge, attitude and practice on folic acid intake among Arabian Qatari women. Reproductive toxicology. 2006; 21(1):21-5.

13. Daly S, Mills J, Molloy A, Kirke P, Scott J. Folic acid food fortification to prevent neural tube defects. The Lancet. 1998; 351 (9105):834-5.

14. Canadian Perinatal Surveillance System, Rusen ID. Congenital anomalies in Canada: a perinatal health report, 2002. Canadian Perinatal Surveillance System; 2002.

15. Shaw GM, Schaffer D, Velie EM, Morland K, Harris JA. Periconceptional vitamin use, dietary folate, and the occurrence of neural tube defects. Epidemiology. $1995 ; 1: 219-26$.
16. McDonald SD, Perkins SL, Jodouin CA, Walker MC. Folate levels in pregnant women who smoke: an important gene/environment interaction. American journal of obstetrics and gynecology. 2002; 187(3):6205.

17. Czeizel AE, Medveczky E. Periconceptional multivitamin supplementation and multimalformed offspring. Obstetrics \& Gynecology. 2003; 102(6):125561.

18. Al-Holy M, Eideh AA, Epuru S, Abu-Jamous D, Ashankyty I. Awareness of Folic Acid Intake among Women in the Childbearing Age in Hail Region-Saudi Arabia. 2013

19. Tilford JM, Grosse SD, Robbins JM, Pyne JM, Cleves MA, Hobbs CA. Health state preference scores of children with spina bifida and their caregivers. Quality of Life Research. 2005; 14(4):1087-98.

20. Pallant, J. SPSS survival manual, United Kingdom: Open University Press. 2005.

21. Nunnally J. C. (1978). Psychometric theory.

22. Peter JP. Reliability: A review of psychometric basics and recent marketing practices. Journal of marketing research. 1979; 1:6-17.

23. Polit DF, Beck CT. Nursing research: Generating and assessing evidence for nursing practice. Lippincott Williams \& Wilkins; 2008.

24. Ali S, Taverner BC, Ghani M, Kussor Z, Naz S. Knowledge of triage among nurses in emergency units. Biomedica. 2013; 1; 29(4).

25. Sen CK, Khanna S, Roy S. Tocotrienols: vitamin E beyond tocopherols. Life sciences. 2006 Mar 27; 78(18):2088-98.

26. Bjelakovic G, Nikolova D, Gluud LL, Simonetti RG, Gluud $\mathrm{C}$. Mortality in randomized trials of antioxidant supplements for primary and secondary prevention: systematic review and meta-analysis. Jama. 2007; 297(8):842-57.

27. Bolander FF. Vitamins: not just for enzymes. Current opinion in investigational drugs (London, England: 2000). 2006 Oct; 7(10):912-5.

28. Maton A. Human biology and health. Prentice Hall; 1997.

29. Asindi A, Al-Shehri A. Neural tube defects in the Asir region of Saudi Arabia. Annals of Saudi medicine. 2001; $21(1 / 2): 26-9$. 
30. Black RE, Cousens S, Johnson HL, Lawn JE, Rudan I, Bassani DG, Jha P, Campbell H, Walker CF, Cibulskis $\mathrm{R}$, Eisele $\mathrm{T}$. Global, regional, and national causes of child mortality in 2008: a systematic analysis. The lancet. 2010; 375(9730):1969-87.

31. Black RE, Allen LH, Bhutta ZA, Caulfield LE, De Onis M, Ezzati M, Mathers C, Rivera J, Maternal and Child Undernutrition Study Group. Maternal and child undernutrition: global and regional exposures and health consequences. The lancet. 2008; 371(9608):243-60.

32. Ota E, Tobe-Gai R, Mori R, Farrar D. Antenatal dietary advice and supplementation to increase energy and protein intake. Cochrane Database Syst Rev. 2012 Sep; 9.
33. Green-Raleigh K, Carter H, Mulinare J, Prue C, Petrini J. Trends in folic Acid awareness and behavior in the United States: the Gallup Organization for the March of Dimes Foundation surveys, 1995-2005. Maternal and child health journal. 2006; 10(1):177-82.

34. Alakhfash AA, Abdulla AM, Osman AM, Abdulgafar JI, Almesned AA. Maternal knowledge and use of folic acid among Saudi females. Saudi medical journal. 2013; 34(11):1173-8.

35. Riazi H, Bashirian S, Amini L. Awareness of pregnant women about folic acid supplementation in Iran. Journal of Family and Reproductive Health. 2012;6(4):159-63.

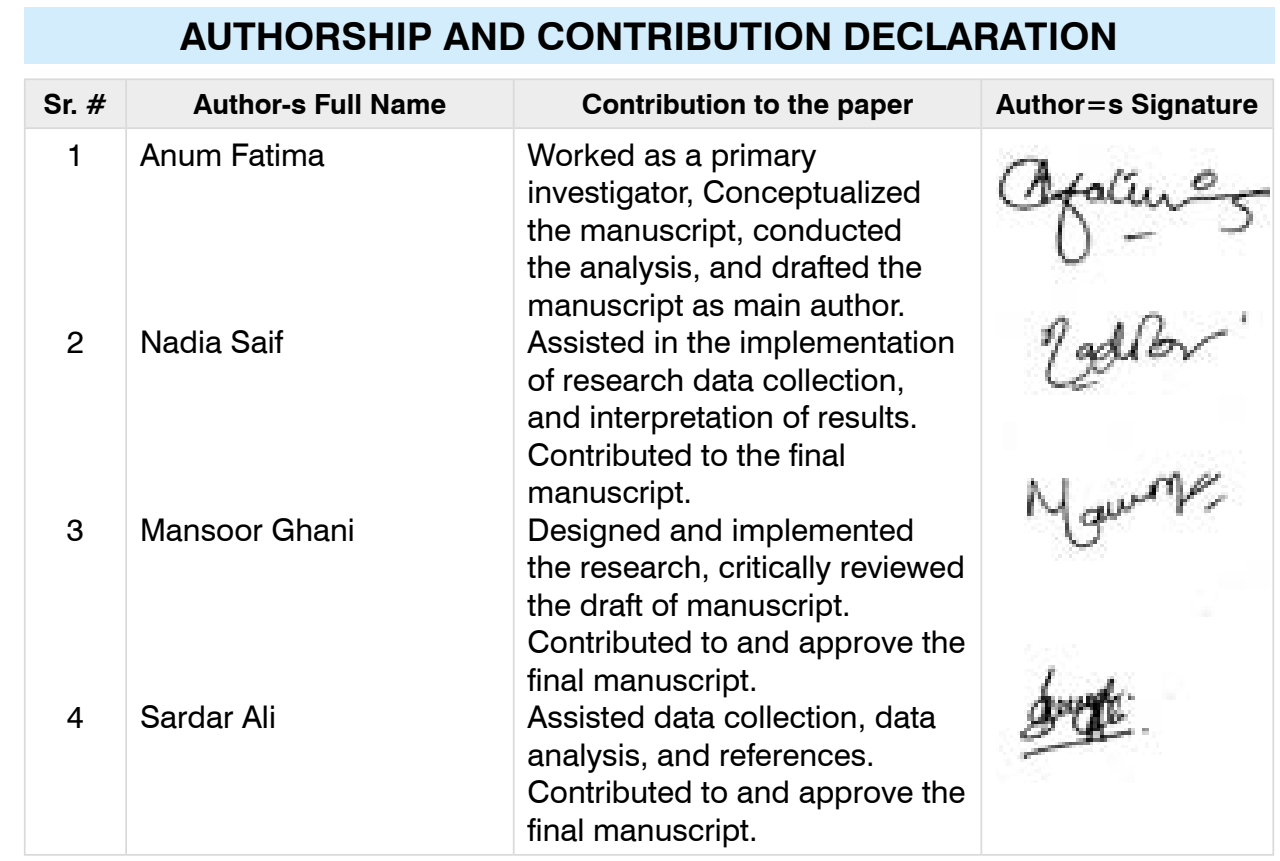

